\title{
Resin Bonding to Silicatized Zirconia with Two Isocyanatosilanes and a Cross-linking Silane. Part II: Mechanistic Approach
}

\author{
Christie Y. K. Lung • Jukka P. Matinlinna
}

Received: 16 April 2010 / Accepted: 13 May 2010 /Published online: 5 June 2010

(C) The Author(s) 2010. This article is published with open access at Springerlink.com

\begin{abstract}
In this paper we discuss and interpret the results of shear bond strengths achieved after the use of two silane coupling agents with isocyanato functionality, viz. 3-isocyanatopropyltrimethoxysilane and 3isocyanatopropyltriethoxysilane. The silanes were used alone and also blended with a non-functional crosslinking silane on silicatized zirconia before light-curing of resin stubs on the surface, as described elsewhere in the first part of our study (see "Part I: Experimental"). A series of reaction mechanisms and conceptual diagrams are also presented. The reaction mechanisms illustrating the effect of adding a cross-linking silane into a silane blend, the silane hydrolysis and the behavior of two organofunctional groups (isocyanate and alkene) of silanes upon reaction with Rely X Unicem Aplicap resin-composite cement are discussed in detail.
\end{abstract}

Keywords Bimolecular nucleophilic substitution $\left(\mathrm{S}_{\mathrm{N}} 2\right)$ reaction - Transition state - Siloxane network - Free radical reaction $\cdot 3$-isocyanatopropyltriethoxysilane .

3-isocyanatopropyltrimethoxysilane $\cdot$ Cycloaddition

\section{Introduction}

Isocyanatosilanes, especially 3-isocyanatopropyltriethoxysilane, has widespread applications in many areas. Examples in the medical sciences include the preparation of molecular valves to regulate the flow of gases or liquids by blocking and

C. Y. K. Lung $(\bowtie) \cdot$ J. P. Matinlinna

Dental Materials Science, Faculty of Dentistry,

The University of Hong Kong,

34 Hospital Road, Sai Ying Pun,

Hong Kong SAR, People's Republic of China

e-mail: yklung@graduate.hku.hk opening passageways [1] and the modification of poly (ethylene glycol) as a sol-gel film deposited on stainless steel to reduce the activation and adhesion of platelets [2]. Furthermore, isocyanatosilanes have been noted on the basis of their potential as coupling agents to bond resin cement and titanium in dentistry [3]. 3-isocyanatopropyltriethoxysilane is a typical bifunctional silane coupling agent, in that it has an organofunctional part connected with a linker (a propylene group) to hydrolyzable alkoxy groups, in this case ethoxy groups.

Results from our study of the effects of using silanes with hydrolyzable alkoxy groups, adding a cross-linking silane and using silanes with different organofunctional groups on the shear bond strength between resin and silicatized zirconia were reported in "Part I: Experimental" [4]. In this study, an approach to explain the experimental results by means of a series of proposed reaction mechanisms are discussed and presented in conceptual diagrams. All the reactions described may yield several products during the course of the reaction, such as in a free-radical reaction. Only one of the products, however, will be considered to simplify the real situation. The mechanistic study and discussion do not include the effect of the linker part (i.e. length) of the isocyanatosilane molecules.

\section{Discussion}

On the basis of our results, we firstly found a difference in shear bond strengths measured for different hydrolyzable groups in silanes, although this was statistically insignificant for $0.1 \mathrm{vol} \%(p=0.205)$ and $1.0 \mathrm{vol} \%(p=0.952)$ between 3-isocyanatopropyltrimethoxysilane and 3isocyanatopropyltriethoxysilane. Secondly, there were statistically significant differences in shear bond strengths for 


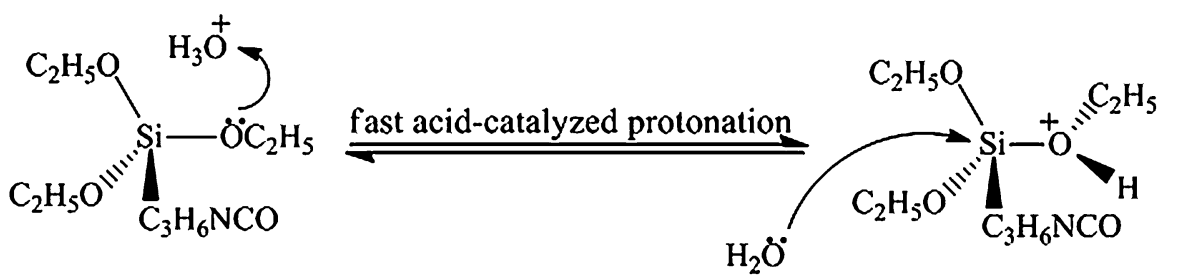

attack from the opposite side

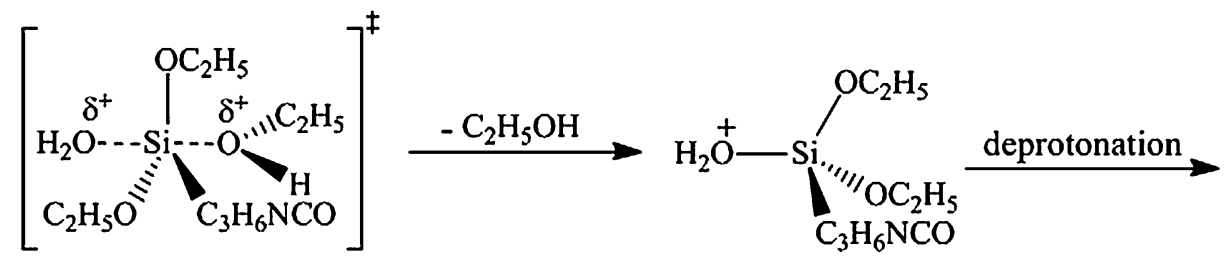
trigonal bipyramidal transition state $\left(\mathrm{sp}^{3} \mathrm{~d}\right.$ hybridization of $\left.\mathrm{Si}\right)$

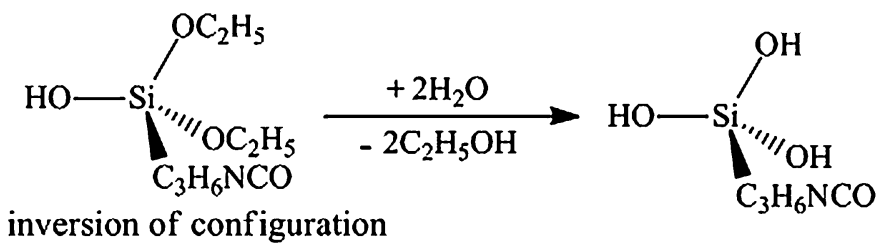

Scheme $1 \mathrm{~S}_{\mathrm{N}} 2$ reaction mechanism showing 3-isocyanatopropyltriethoxysilane hydrolysis in acidic medium (modified from ref. 5)

addition of a cross-linking silane for $0.1 \mathrm{vol} \%(p<0.01)$ and $1.0 \mathrm{vol} \%(p<0.04)$ of 3 -isocyanatopropyltrimethoxysilane but not for $0.1 \mathrm{vol} \%(p=0.403)$ and $1.0 \mathrm{vol} \%(p=0.562)$ of 3-isocyanatopropyltriethoxysilane. Thirdly, there was a statistically significant difference in shear bond strengths between different organofunctional groups of silanes, 3-methacryloxypropyltrimethoxysilane, $0.1 \mathrm{vol} \%$ and 1.0 vol\% of both 3 -isocyanatopropyltrimethoxysilane and 3-isocyanatopropyltriethoxysilane $(p<0.02)$. After surveying the literature and applying general principles of organic chemistry and polymer chemistry, we have proposed a series of reaction mechanisms and conceptual diagrams to explain these results [4] in three main areas: hydrolysable groups of silanes, cross-linking silanes and organofunctional groups of silanes.

\subsection{Effect of Chain Length of the Alkoxy Groups of the Isocyanato Silane on the Shear Bond Strengths}

The isocyanato silane is activated by hydrolysis before it can couple to the silicatized zirconia surface. The first hydrolysis step of silane to silanol $(\equiv \mathrm{SiOH})$ is a fast and reversible protonation of the alkoxy group of the silane which enhances the leaving group ability. Then, it is followed by a bimolecular nucleophilic substitution $\left(\mathrm{S}_{\mathrm{N}} 2\right)$ reaction [5]. This involves the backside attack of a nucleophile (an electron-rich species) to the electrophile (an electron-deficient species), i.e the central silicon atom, to produce a penta-coordinate trigonal bipyramidal transition state. A new bond is then formed between the nucleophile (water) and the silicon atom, and a bond is cleaved between the leaving group (alcohol) and the silicon atom which gives the final product with inversion of configuration $[6,7]$.

Chambers et al. [5] have studied the steric and inductive effects of alkoxy groups on the acid-catalyzed hydrolysis of ethyltrimethoxysilane and tetramethoxysilane. An alkoxy

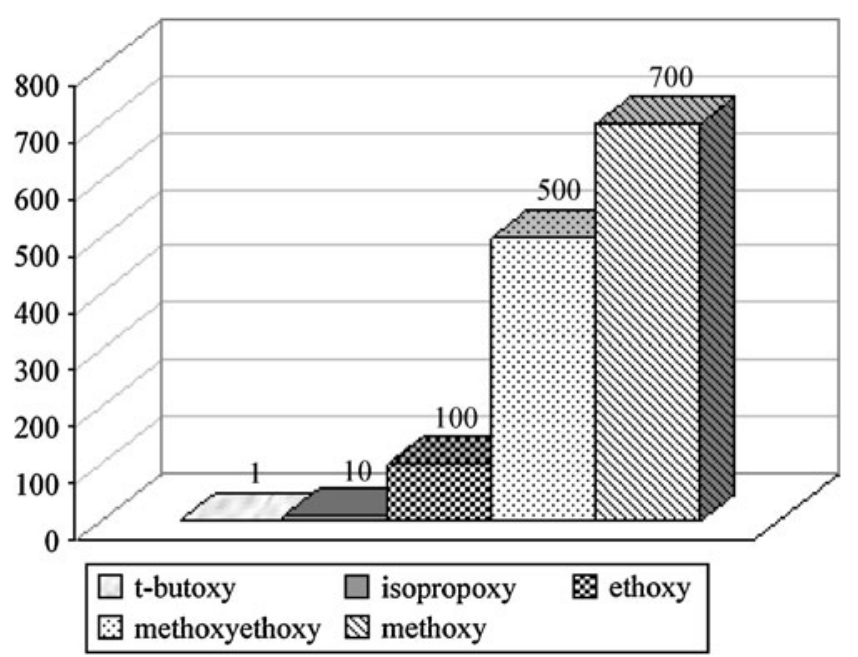

Fig. 1 Relative rates of hydrolysis of hydrolyzable groups of silanes [modified from ref. 9]. The numbers on the y-axis are the relative ratios of the hydrolysis rate 
Fig. 2 The effect of using a cross-linking silane, blended with a functional silane, on a silica-coated zirconia surface. Key: ICMS = 3-isocyanatopropyltrimethoxysilane, BTSE = bis-1,2-(triethoxysilyl) ethane, Rely X Unicem Aplicap resin = an adhesive bifunctional resin cement

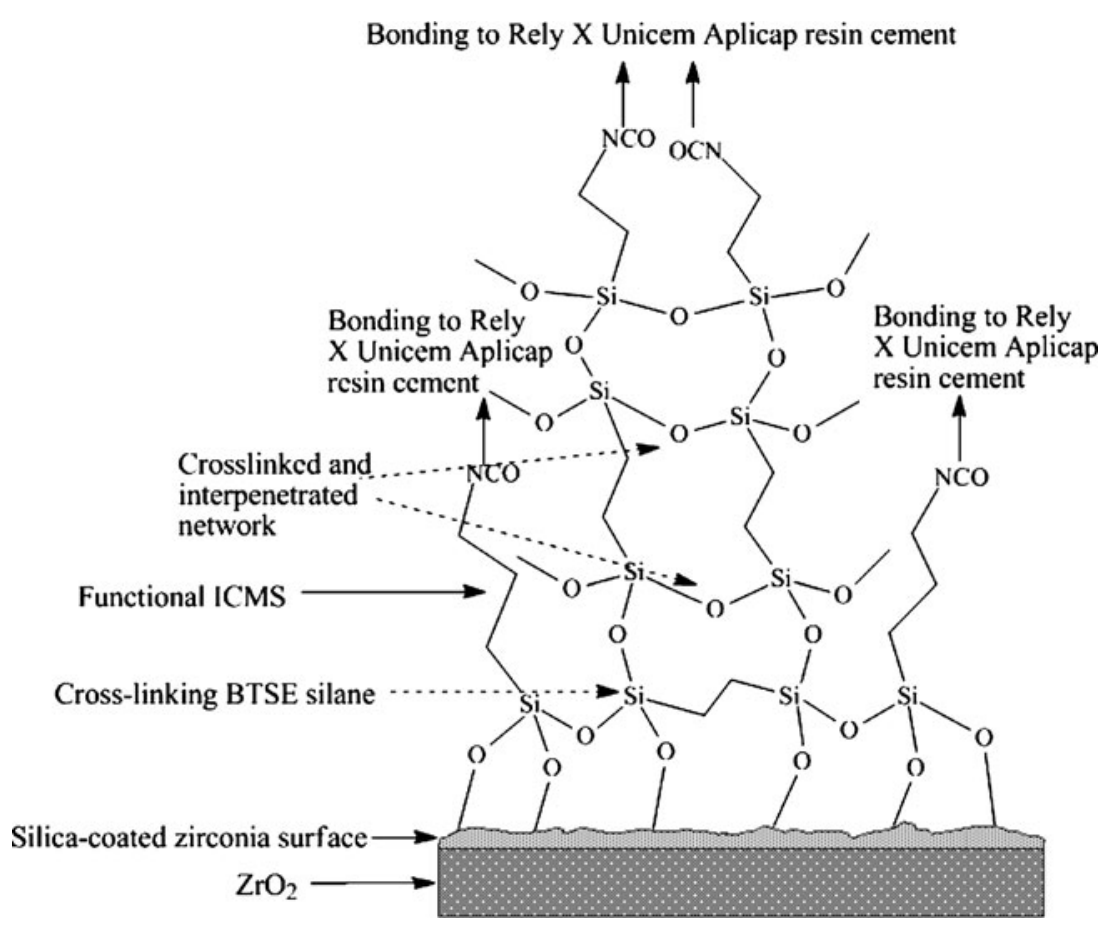

group is a better electron-donating substituent than a hydroxyl group and so the rate of hydrolysis should decrease with more hydroxyl substitutions. However, the results revealed the second and third steps of hydrolysis were about two to three times faster than in the first hydrolysis step with successive hydroxyl substitutions. The differences in rate of the second and of the third hydrolysis steps for the two silanes were comparably small which proved the rate of hydrolysis was little affected by further hydroxyl substitutions. This is due to the relief of steric strain after leaving of a bulky alkoxy group in the first step of the hydrolysis. After that, the two monomers would be equally reactive in the second and the third hydrolysis steps. They concluded that steric effect was the dominant factor over the inductive effect affecting the rate of silane hydrolysis.
The ethoxy group of 3-isocyanatopropyltriethoxysilane is more sterically bulky than the methoxy group of 3isocyanatopropyltrimethoxysilane. This additional bulk would increase steric repulsion when the incoming nucleophile (water in this case) attacks the central silicon atom. As a result, more energy is needed to form the transition state [7]. The reaction rate of nucleophilic substitution for 3isocyanatopropyltriethoxysilane is thus decreased. A suggested reaction mechanism illustrating the hydrolysis of 3 -isocyanatopropyltriethoxysilane is shown in Scheme 1 [modified from ref. 5].

In our study of the effect of chain length of alkoxyl hydrolyzable groups of isocyanato silane on the shear bond strength between Rely X Unicem Aplicap resin cement and silicatized zirconia, the results were statistically insignifi-
Fig. 3 Resonance structure showing electron delocalization in 3-methacryloxypropyltrimethoxysilane (after hydrolysis) free radical. Key: $\mathrm{I}=$ initiator in Rely X Unicem Aplicap resin cement

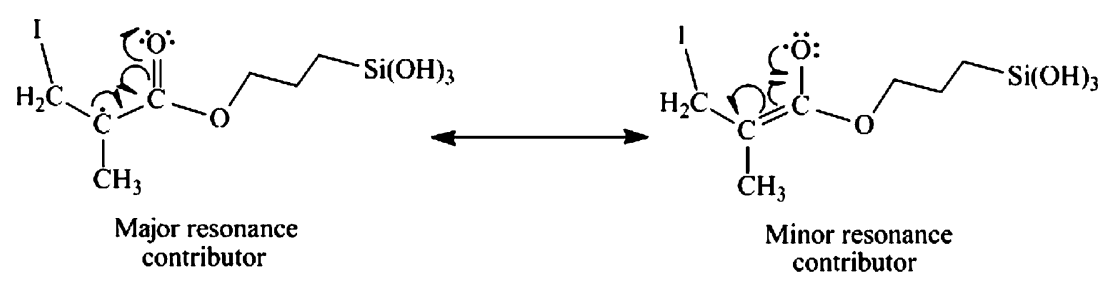

or<smiles>CC(CI)=C([O-])OCCC[SiH3]</smiles> 
cant for the two silanes tested. Rely X Unicem Aplicap is a modern multipurpose resin-composite luting cement used in dentistry, and it contains both methacrylate and phosphate ester groups [8]. The similar findings for resin-zirconia bonding for the two silanes may be explained by the rapid hydrolysis of 3-isocyanatopropyltrimethoxysilane and 3isocyanatopropyltriethoxysilane, such that hydrolysis is probably almost complete within $1 \mathrm{~h}$. However, as the size of the hydrolyzable groups increases from ethoxy to isopropoxy or even to tert-butoxy, the effect is pronounced (Fig. 1) [9]. If, for example, a ten minutes hydrolysis time was required for methoxy silane, then tert-butoxy silane would require about $7000 \mathrm{~min}$ (viz. $700 \times 10 \mathrm{~min}$ ) for hydrolysis at the same silane concentration, at constant $\mathrm{pH}$ and at room temperature. Also, the linker part of the silane molecule is invariable.
2.2 Effect of Addition of Cross-linking Silane on the Shear Bond Strength

The results reported in "Part I: Experimental" showed that there was a statistically significant difference in the measured shear bond strength when cross-linking silane, bis-1,2-(triethoxysilyl)ethane, was added to the functional silane 3 -isocyanatopropyltrimethoxysilane $(p<0.04$ for $0.1 \mathrm{vol} \%$ and $p<0.01$ for $1.0 \mathrm{vol} \%$ ). The function of adding cross-linking silane is to enhance the adhesion by strengthening the siloxane network through extensive three dimensional cross-linking and interpenetration of monomers, thereby interconnecting the functional silane (Fig. 2) [10]. As a consequence, a rigid siloxane network is formed and evidently more energy is required to break apart the cross-
Scheme 2 Reaction mechanism showing free-radical reaction between 3-methacryloxypropyltrimethoxysilane and methacrylate monomer. Key: $\mathrm{I}=$ initiator in Rely X Unicem Aplicap resin cement

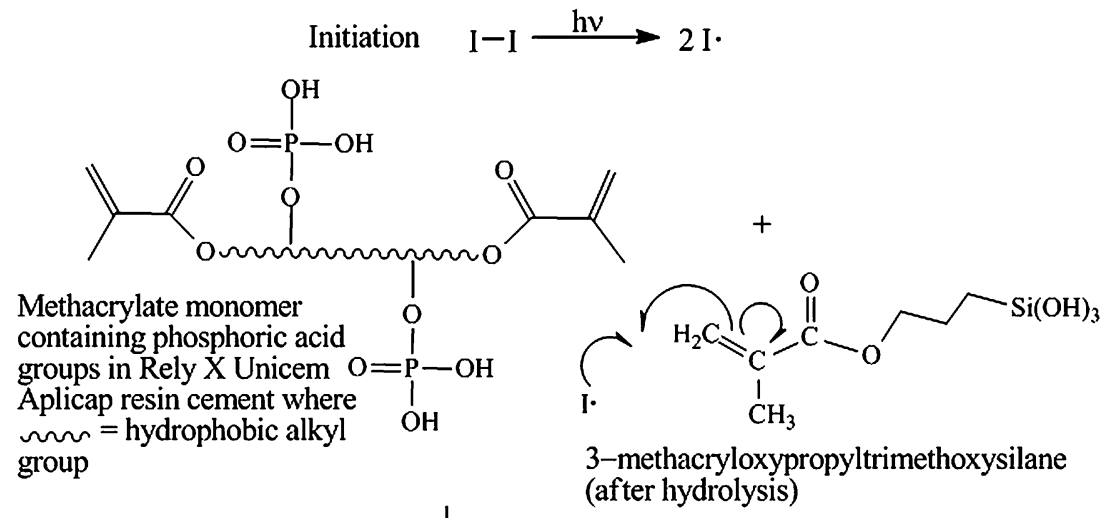

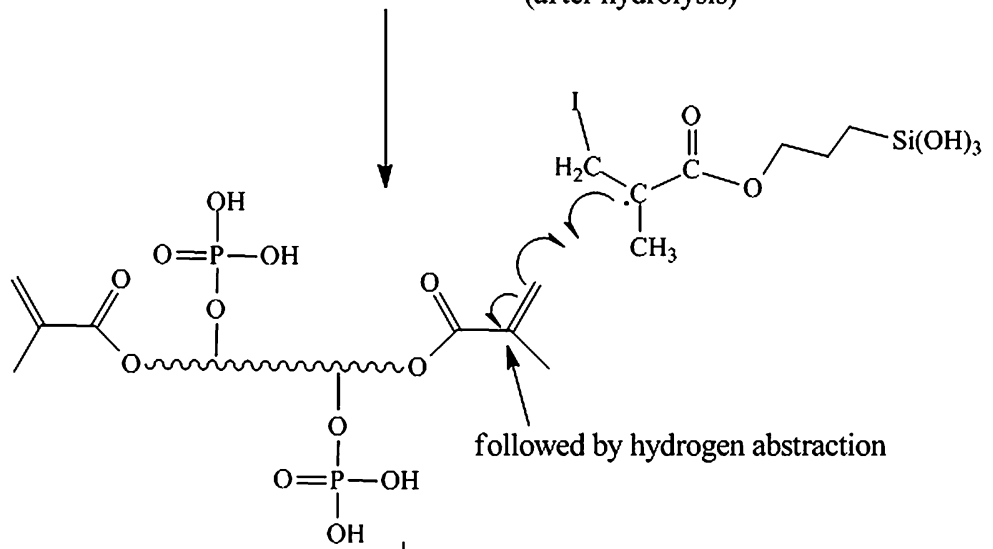

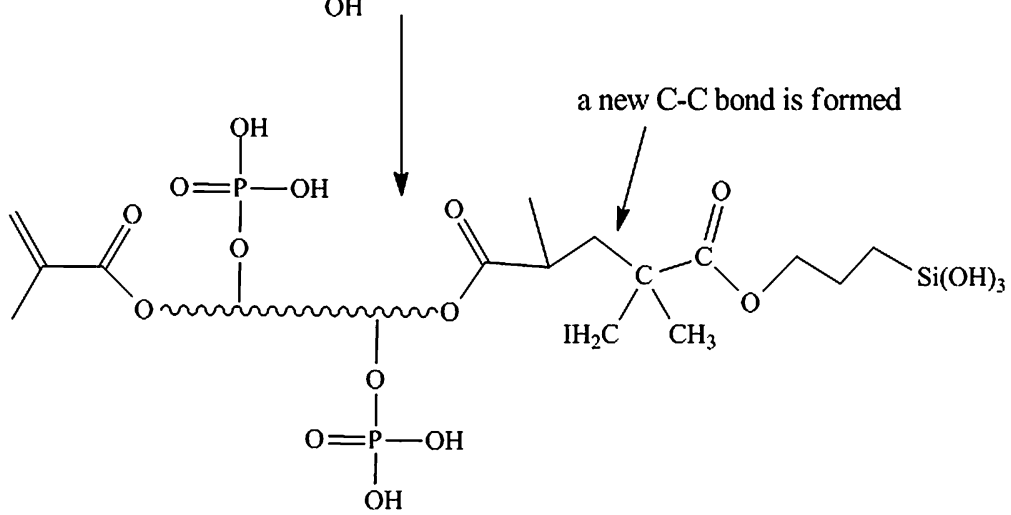


linking network before a bonded specimen can be debonded from the substrate.

\subsection{Effect of Different Organic Functional Groups} of Functional Silanes on the Shear Bond Strength

The resin cement used in this study was 3 M ESPE Rely X Unicem Applicap. This product consists of methacrylate monomers, phosphoric acid groups (phosphate esters) and a relatively long hydrophobic alkyl-group backbone (the exact length is not revealed in the literature). The $>\mathrm{C}=\mathrm{C}<$ bond in the methacrylate monomers is prone to react with organic functional groups of bifunctional silanes to form a new covalent bond. In our study, the reaction was initiated by photons generated at a wavelength between $400 \mathrm{~nm}$ and $500 \mathrm{~nm}$ by a light-curing unit (Elipar 2500 Halogen Curing Light, $3 \mathrm{M}$ ESPE) for $40 \mathrm{~s}$, as stipulated by the manufacturer. The nature of the organic functional groups greatly affects the reaction rate during the light-curing process since the reaction rate depends on the activation energy of the reaction according to the Arrhenius equation (eqn. 1) [11].

$\mathrm{K}=\mathrm{Ae}^{-\mathrm{Ea} / \mathrm{RT}}$

where $\mathrm{k}$ is the rate constant, $\mathrm{A}$ is the frequency factor, $\mathrm{E}_{\mathrm{a}}$ is the activation energy of the reaction, $\mathrm{R}$ is the gas constant and $\mathrm{T}$ is the temperature which is constant (room temperature) in this study.
Scheme 3 Reaction mechanism showing photochemical [2+2] cycloaddition between 3-isocyanatopropyltrimethoxysilane and methacrylate monomer
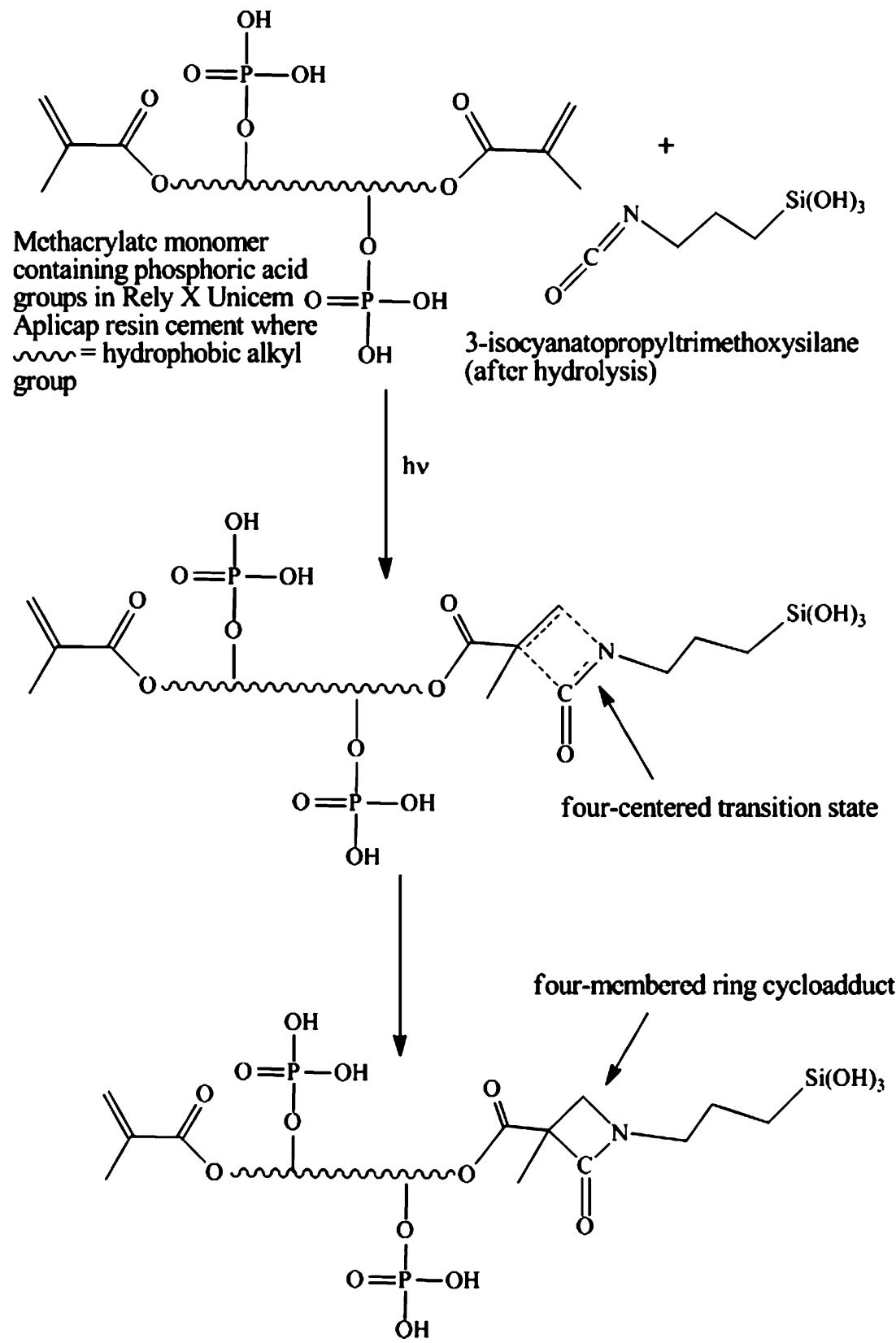
The organic functional group in 3-isocyanatopropyltriethoxysilane and 3-isocyanatopropyltrimethoxysilane is an isocyanato, $-\mathrm{NCO}$, group and in the control silane, which contains 3-methacryloxypropyltrimethoxysilane, the organic functional group is a vinylic $>\mathrm{C}=\mathrm{C}<$ group.

The reactive component in $3 \mathrm{M}$ ESPE Sil silane is a prehydrolyzed oligomeric form of 3-methacryloxypropyltrimethoxysilane. For simplicity, only the monomeric form is considered in the reaction mechanism. The reaction between 3-methacryloxypropyltrimethoxysilane and the monomers in Rely X Unicem Aplicap resin cement is a free-radical reaction. The initiator components in the resin cement decompose to form free radicals by blue light energy in the region of $400-500 \mathrm{~nm}$. When a radical is formed, it adds to the $\alpha$ carbon atom in a carbon-carbon $\pi$ bond adjacent to the carbonyl group, which is broken homolytically in 3-methacryloxypropyltrimethoxysilane. The radical is stabilized by electron delocalization over the carbonyl group (Fig. 3). Once this radical is formed, it adds to the carbon-carbon $\pi$ bond in methacrylate monomers to form a carbon-carbon $\sigma$ bond [12], which gives the final addition product. The suggested free-radical reaction mechanism is shown in Scheme 2.
For the isocyanato silane, the $-\mathrm{NCO}$ group reacts with the $>\mathrm{C}=\mathrm{C}<$ bond in methacrylate monomers containing phosphoric acid groups in the Rely X Unicem Aplicap resin cement, to form a four-membered ring compound by photochemical [2+2] cycloaddition. The suggested photochemical cycloaddition mechanism is shown in Scheme 3.

By using semi-empirical methods and ab initio theory, Williams and Whitehead [13] and Cossío et al. [14] proved that the cycloaddition reaction between isocyanate and alkene was a concerted [2+2] cycloaddition. In other words, bond breaking and bond making occur in one step, without the involvement of any intermediates. The cycloaddition product of isocyanate to methacrylate monomer was a fourmembered ring compound in which one of the carbon atoms is $\mathrm{sp}^{2}$ hybridized and the other two and the nitrogen atom are $\mathrm{sp}^{3}$ hybridized. The optimum geometry for $\mathrm{sp}^{2}$ hybridization is trigonal planar with a bond angle of $120^{\circ}$. For $\mathrm{sp}^{3}$ hybridization, the bonds follow the four directions connecting the center of a regular tetrahedron to its four corners, with a bond angle of $109.5^{\circ}$. However, the lone pair of electrons in the nitrogen atom causes the bond angles to be compressed to $107^{\circ}$. The bond angle of both the carbon and the nitrogen atoms in the cycloadduct is approximately $90^{\circ}$, which causes
Fig. 4 a. Hypothetical potential energy diagram for the freeradical addition of 3-methacryloxypropyltrimethoxysilane (MPS) to methacrylate monomer. b. Hypothetical potential energy diagram for the photocycloaddition of 3-isocyanatopropyltrimethoxysilane (ICMS) to methacrylate monomer. $\mathrm{E}_{1}$ and $\mathrm{E}_{2}$ correspond to the activation energy barrier of the reactions with $E_{2}>E_{1}$
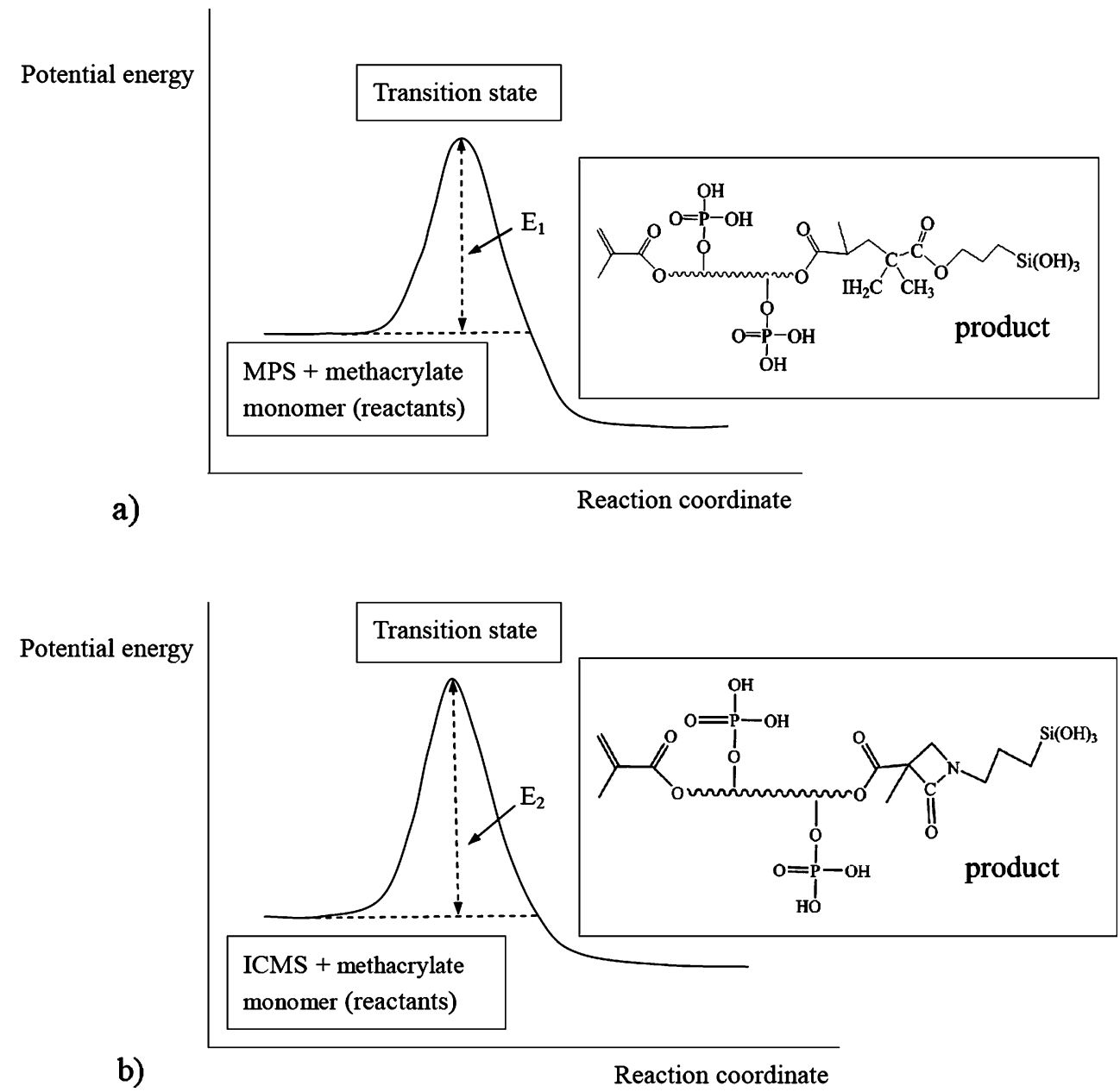
severe bond angle distortion $\left(120^{\circ} \rightarrow 90^{\circ}\right.$ for carbonyl $\mathrm{C}$, $109.5^{\circ} \rightarrow 90^{\circ}$ for other two $\mathrm{C}$ and $107^{\circ} \rightarrow 90^{\circ}$ for $\left.\mathrm{N}\right)$. Thus, the stability of the compound is lowered because of ring strain [15]. More energy is then needed for the transition state to overcome the ring strain to form the product. The addition product derived from 3-methacryloxypropyltrimethoxysilane and a methacrylate monomer is more stable than that from 3-isocyanatopropyltrimethoxysilane and methacrylate monomer. The activation energy barrier for the cycloaddition of 3-isocyanatopropyltrimethoxysilane and methacrylate monomer was thus greater than that of 3-methacryloxypropyltrimethoxysilane and methacrylate monomer.

Hypothetical potential energy diagrams, in arbitrary units, for the two reactions have been drawn to clarify the picture more clearly (Fig. 4). The rate of the reaction depends largely on the ease of transition state formation at constant temperature. The potential energy of the transition state of the cycloadduct is higher than that of the addition product. Therefore, the rate of the product formation from free-radical reaction is faster than from cycloaddition. This difference might explain why the shear bond strength of Rely X resin cement to silicatized zirconia that had been silanized with 3-methacryloxypropyltrimethoxysilane was greater than that of silicatized zirconia that had been silanized with 3-isocyanatopropyltrimethoxysilane or 3isocyanatopropyltriethoxysilane under the same preparation conditions (light-curing for $40 \mathrm{~s}$ at room temperature).

\section{Conclusions}

The experimental results reported in "Part I: Experimental" [4] have been explained in terms of reaction mechanisms and conceptual diagrams. It can be concluded and suggested that the shear bond strength between resin cement and silicatized zirconia depends on the following:

a) The sizes of hydrolyzable groups of the silanes for a given period of duration of hydrolysis.

b) The addition of a cross-linking agent, in this case bis1,2-(triethoxysilyl) ethane, with the functional silane. c) The types of organofunctional groups of the silane that react with the resin monomers of the resin-composite cement.

Acknowledgements This study was financially supported from the research grants (Seed Funding Programme for Basic Research \#200905159006) of the University of Hong Kong. Dr. Barry Arkles from Gelest Inc. is thanked for generously providing silane monomers to our study. The authors wish to thank Dr. Trevor Lane the University of Hong Kong for proofreading the manuscript.

Open Access This article is distributed under the terms of the Creative Commons Attribution Noncommercial License which permits any noncommercial use, distribution, and reproduction in any medium, provided the original author(s) and source are credited.

\section{References}

1. Nguyen TD, Tseng H-R, Celestre PC, Flood AH, Liu Y, Stoddart JF, Zink JI (2005) Proc National Acad Sci 102:10029

2. Okner R, Domb AJ, Mandler D (2009) New J Chem 33:1596

3. Matinlinna JP, Lassila LVJ, Kangasniemi I, Vallittu PK (2005) J Dent Res 84:360

4. Lung CYK, Matinlinna JP (2010) Silicon in press

5. Chambers RC, Jones WE, Haruvy Y, Webber SE, Fox MA (1993) Chem Mater 5:1481

6. Bento AP, Bickelhaupt FM (2007) J Org Chem 72:2201

7. Peter K, Vollhardt C, Schore NE (2003) Organic chemistry: structure and function, W. H. Freeman and Company, 4th edn, pp 209-235

8. 3M ESPE Rely X Unicem Self-Adhesive Universal Resin Cement Technical Product Profile. 2002, pp 10. (http://www.3m.com/intl/kr/ medi/medi5/product/RelyX\%20Unicem.pdf)

9. Arkles B (2006) Silane coupling agents: connecting across boundaries v2.0. Gelest, Inc. pp 15

10. Matinlinna J, Özcan M, Lassila L, Kalk W, Vallittu P (2008) Acta Odont Scand 66:250

11. Atkins P, Paula de P (2002) Atkins' physical chemistry, Oxford University Press, 7th edn, pp 879-881

12. Billmeyer FW, JR (1984) Textbook of polymer science, 3rd edn, John Wiley \& Sons, Inc., NY, Ch. 3. pp 49-75

13. Williams CI, Whitehead MA (1999) J Molec Struct (Theochem) 491:93

14. Cossío FP, Lecea B, Lopez X, Roa G, Arrieta A, Ugalde JM (1993) J Chem Soc Chem Commun 18:1450

15. Winnik MA (1981) Chem Rev 81:491 